\title{
Role of prothrombin complex concentrate in perioperative coagulation therapy
}

\author{
Kenichi A Tanaka ${ }^{1 *}$, Michael Mazzeffi ${ }^{1}$ and Miroslav Durila ${ }^{2}$
}

\begin{abstract}
Prothrombin complex concentrate (PCC) is a term to describe pharmacological products that contain lyophilized, human plasma-derived vitamin K-dependent factors (F), FII, FVII, FIX, FX, and various amounts of proteins C and S. PCCs can be rapidly reconstituted in a small volume $(20 \mathrm{ml}$ for about 500 international units (IU)) at bedside and administered regardless of the patient's blood type. PCCs are categorized as 4-factor PCC if they contain therapeutic amounts of FVII, and 3-factor PCC when FVII content is low. In addition, activated PCC which contains activated FVII and FX with prothrombin is available for factor VIII bypassing therapy in hemophilia patients with inhibitors. Currently, 4-factor PCC is approved for the management of bleeding in patients taking warfarin, but there has been increasing use of various PCCs in the treatment of acquired perioperative coagulopathy unrelated to warfarin therapy and in the management of bleeding due to novel oral anticoagulants. There is also an ongoing controversy about plasma transfusion and its potential hazards including transfusion-related lung injury (TRALI). Early fixed ratio plasma transfusion has been implemented in many trauma centers in the USA, whereas fibrinogen concentrate and PCC are preferred over plasma transfusion in some European centers.

In this review, the rationales for including PCCs in the perioperative hemostatic management will be discussed in conjunction with plasma transfusion.
\end{abstract}

Keywords: Coagulation, Fresh frozen plasma, Prothrombin complex concentrate, Recombinant activated factor VII, Factor eight bypassing agent, Thromboelastometry

\section{Introduction}

Clinical management of severe bleeding in surgery and after trauma remains a major challenge. Transfusions of allogeneic platelets and plasma are widely used to replace cellular and humoral components of coagulation. These allogeneic products appear to be lifesaving when they are utilized early in the massive transfusion protocol in which more than six to ten units of packed red blood cells (RBCs) are typically administered in 12-24 $\mathrm{h} \mathrm{[1-3].} \mathrm{On} \mathrm{the}$ other hand, large amounts of allogeneic plasma have been associated with both infectious and non-infectious transfusion complications, which negatively impact patient survival [3-5].

Plasma-derived and recombinant factor concentrates are the lyophilized form of specific factor(s) indicated mainly for hereditary coagulation factor deficiencies [6].

\footnotetext{
*Correspondence: clot.atl@gmail.com

'Department of Anesthesiology, Cardiothoracic Anesthesia Division, University of Maryland, Suite S8D12, 22 South Greene Street, Baltimore, MD 21201, USA

Full list of author information is available at the end of the article
}

The use of these factor concentrates in perioperative patients without hereditary coagulation disorders has been increasingly reported in anecdotal case series, retrospective, and prospective clinical studies $[7,8]$. Off-label use of recombinant activated factor VII (rFVIIa) has been rampant in the management of severe perioperative bleeding until several key clinical trials failed to improve outcomes and suggested a potential increase in thrombotic complications [9]. More recently, the FDA has approved the use of prothrombin complex concentrate (PCC) with therapeutic amounts of vitamin K-dependent factors for the management of bleeding in patients treated with warfarin [10]. For the latter, prothrombin, FVII, FIX, and FX are the specific 'targets' of PCC for replacement. Conversely, if plasma is used to reverse warfarin, multiple unnecessary elements are infused into the patient including albumin, antithrombin, fibrinogen, immunoglobulins, etc. Clinical indications, efficacies, and potential complications of plasma and factor concentrates should be carefully considered before they are applied to correct bleeding diathesis. 
Further, it is important to understand the mechanism of action of hemostatic agents and their impact on coagulation tests so that inappropriate dosing can be avoided.

The goal of this review is to discuss current limitations of plasma transfusion, pharmacology of PCCs, and their potential roles in surgical and trauma settings.

\section{Review}

\section{Limitations of plasma}

In the USA, two types of plasma are generally used for transfusion: fresh frozen plasma (FFP; plasma frozen within $8 \mathrm{~h}$ ) and frozen plasma (FP24; plasma frozen at 8-24 h after collection). Once thawed, FFP and FP24 can be kept in the refrigerator $\left(1^{\circ} \mathrm{C}-6^{\circ} \mathrm{C}\right)$ for 5 days, which potentially reduces plasma wastage and increases the inventories of group $\mathrm{AB}$ (universal) or group $\mathrm{A}$ plasma for emergency transfusion [11]. Although this has become a standard practice at large tertiary care centers in the North America, thawed plasma products may not be an option in smaller hospitals [12] and in other countries (Japan, Germany, etc.) [13].

Coagulation factor levels except for FVIII appear to stable for 5-7 days after thawing as long as plasma bags are kept at $1^{\circ} \mathrm{C}-6^{\circ} \mathrm{C}$ [13-15]. FVIII is most labile, and its activity falls by approximately $40 \%$ in 5 days. Some thawed plasma units (particularly group O plasma) may contain FVIII levels below $50 \%$ at the time of administration [14]. However, this is unlikely to have any clinical consequence because FVIII levels are often normal or elevated in most surgical and trauma patients [16,17]. Anticoagulant levels including antithrombin (AT) and protein $\mathrm{C}$ are also preserved, but protein $\mathrm{S}$ is decreased to $50 \%$ in 5-day old thawed plasma [13].

Although coagulation factor levels remain relatively stable in thawed plasma compared to FFP and FP24, there is a significant variability $(50 \%-150 \%)$ in factor levels among individual donors [18,19]. For example, consider a case where one unit of plasma $(250 \mathrm{ml})$ is being transfused to an $80-\mathrm{kg}$ patient who currently has prothrombin activity of $20 \%(20 \mathrm{IU} / \mathrm{dl})$. Assuming a plasma volume of $50 \mathrm{ml} / \mathrm{kg}$, total amount of prothrombin in this patient is equal to:

$$
80 \mathrm{~kg} \times 50 \mathrm{ml} / \mathrm{kg} \times 0.2 \mathrm{IU} / \mathrm{ml}=800 \mathrm{IU}
$$

If the donor plasma contains $80 \%$ prothrombin activity $(80 \mathrm{IU} / \mathrm{dl})$, the transfused amount of prothrombin is: $250 \mathrm{ml} \times 0.8 \mathrm{IU} / \mathrm{ml}=200 \mathrm{IU}$.

Thus, after transfusion (assuming 100\% recovery), total prothrombin activity is:

$$
(800+200) \mathrm{IU} /(4,000+250) \mathrm{ml}=23.5 \mathrm{IU} / \mathrm{dl}(23.5 \%)
$$

If four units of the same plasma are transfused, total prothrombin activity becomes:

$$
\begin{aligned}
& (800+200 \times 4) \mathrm{IU} /(4,000+250 \times 4) \mathrm{ml} \\
& =32.0 \mathrm{IU} / \mathrm{dl}(32 \%)
\end{aligned}
$$

Similarly, if four units of another donor plasma with $120 \%$ prothrombin activity were transfused, total prothrombin activity becomes:

$$
\begin{aligned}
& (800+300 \times 4) \mathrm{IU} /(4,000+250 \times 4) \mathrm{ml} \\
& =40.0 \mathrm{IU} / \mathrm{dl}(40 \%)
\end{aligned}
$$

Thus, plasma prothrombin activity is expected to be higher after the latter set of plasma, but normal prothrombin level above $50 \%$ is not achieved in this patient at the end of plasma transfusion $(12.5 \mathrm{ml} / \mathrm{kg})$. Indeed, it was previously reported that $30 \mathrm{ml} / \mathrm{kg}$ of plasma were needed to achieve $30 \%$ increase in procoagulant factor levels in critically ill patients with bleeding [20]. Large volumes of plasma transfusion increase not only the risk of transfusion-associated circulatory overload (TACO) but also the risk of transfusion-related acute lung injury (TRALI), a potentially lethal complication of plasma transfusion [21]. The pathogenesis of TRALI presumably involves leukocyte agglutination in pulmonary capillaries, which is triggered by donor antibodies against the recipient's human leukocyte antigen (HLA) and neutrophilspecific antigens (HNA). Multiparous females are often sensitized to HLA antigens, and the recent switch to the preferential use male donor plasma has significantly reduced the incidence of TRALI to 1:12,000 [22]. However, in the emergency setting, about $40 \%$ of $\mathrm{AB}$ plasma is still from female donors, and the risk of TRALI is presumably higher [23]. It is also common to use ABO-compatible plasma, which is not identical to the recipient's $A B O$ group in the case of massive transfusion. In the retrospective matched cohort study of 568 trauma patients, the use of ABO-compatible plasma was dose-dependently associated with increased risks of acute respiratory distress syndrome and sepsis compared to the use of ABO-identical plasma [5].

Taken together, plasma transfusion should be implemented in the early phase of resuscitation for massive hemorrhage when bleeding sites are unknown, or no surgical control of bleeding has been achieved. Large volumes of required plasma $(15-30 \mathrm{ml} / \mathrm{kg})$ are usually tolerated because of hypovolemia due to hemorrhage. The risks of TRALI and other complications are theoretically increased after the exposure to multiple plasma units and donor antibodies. Newer commercial plasma products such as solvent-detergent plasma appear to have a minimal TRALI risk (i.e., anti-HLA/anti-granulocyte antibodies are significantly diluted by pooling of plasma from approximately 1,500 donors) [24], but it has not been widely used in the North America. 


\section{PCCs versus plasma in acute warfarin reversal}

PCC is a term used for lyophilized, human plasmaderived vitamin K-dependent coagulation factor concentrate. There are a number of commercial PCC products, and their availability varies among countries. According to the contents of coagulation factors, they are categorized into three groups: 4-factor PCC, 3-factor PCC, and activated PCC (Table 1).

The FDA approval of 4-factor PCC for acute warfarin reversal was based on the multicenter prospective randomized study of Kcentra (CSL Behring, Marburg, Germany) and FFP in warfarin-treated adult patients (international normalized ratio (INR) >2.0) undergoing urgent surgery or invasive procedure [10]. This study demonstrated important differences in clinical endpoints and hematological parameters between 4-factor PCC and FFP. First, clinical hemostasis over $24 \mathrm{~h}$ with 4factor PCC was non-inferior to FFP $(72.4 \%$ vs. $65.4 \%$, respectively). However, the median volume of infusion was much less for PCC than FFP ( 99.4 vs. $813.5 \mathrm{ml}$, respectively). Secondly, the target INR of $\leq 1.3$ was reached after 30 min of intervention in $62.2 \%$ of patients treated with 4-factor PCC versus only in $9.6 \%$ of FFP-treated patients. It is also important to point out that the median time required to complete the treatment was much less for PCC than FFP (17.0 vs. 148 min, respectively).

Lastly, rapid recoveries of plasma vitamin $\mathrm{K}$ factor levels were clearly demonstrated within $30 \mathrm{~min}$ after infusing 4-factor PCC, while it took at least $3 \mathrm{~h}$ for plasma transfusion (and vitamin $\mathrm{K}$ ) to bring procoagulant levels to $\geq 50 \%$ [10]. In particular, prothrombin (FII) and FX were recovered to $80 \%-100 \%$ of normal activity and maintained for $24 \mathrm{~h}$ with 4 -factor PCC compared to plasma (Figure 1). Initial recoveries of FVII and FIX to
60\%-80\% were also better for 4-factor PCC than for plasma transfusion, but no difference between PCC and plasma was observed after $12 \mathrm{~h}$.

3-factor PCC and activated PCC (factor eight bypassing agent; FEIBA) are specifically indicated for the prevention and treatment of hemophilia-related bleeding. However, 3 -factor PCC is rarely used for this indication because human plasma-derived and recombinant FIX are available for hemophilia B. The use of 3-factor PCC for acute warfarin reversal has been reported prior to the approval of 4factor PCC [24-27]. When INR values are very high (>5.0), 3 -factor PCC is less effective than 4-factor PCC because FVII content is subtherapeutic in 3-factor PCC $[24,28]$. However, 3-factor PCC appears to be hemostatically effective due to high contents of FX and prothrombin [25-27]. Activated PCC (FEIBA) contains non-activated FII, FIX, and FX as well as trace amounts of FVIIa and FXa [29]. This agent is used in hemophilia patients with neutralizing antibodies to FVIII or FIX. The off-label use of FEIBA (500-1,000 IU) was shown to be more effective than 2-4 units of FFP in acute warfarin reversal [30].

The manufacturing process of PCCs from pooled human plasma includes pathogen reduction steps to prevent the transmission of lipid-enveloped viruses. These steps are solvent detergent exposure, pasteurization in the aqueous phase, or exposure of lyophilized product to vapor heat. There is a remaining concern for the transmissions of non-lipid enveloped, heat-resistant viruses including parvovirus B19 or variant CreutzfeldtJakob disease (VCJD; bovine spongiform encephalopathy (BSE)), and other emerging pathogens, but strict donor screening, nanofiltration of the source plasma, and inventory hold should sufficiently lower the risk of such transmissions [31].

Table 1 Factor contents of commercially available PCCs

\begin{tabular}{|c|c|c|c|c|c|c|c|}
\hline & FII IU/ml & $\mathrm{FVII} \mathrm{IU/ml}$ & $\mathrm{FIX} \mathrm{IU/ml}$ & $\mathrm{FX} \mathrm{IU/ml}$ & $\mathrm{PC} \mathrm{IU/ml}$ & $\mathrm{PS}$ IU/ml & Hepari U/ml \\
\hline \multicolumn{8}{|l|}{ 4-factor PCC } \\
\hline Beriplex/Kcentra (CSL Behring, Germany) & $20-48$ & $10-25$ & $20-31$ & $22-60$ & $15-45$ & $13-26$ & $0.4-2$ \\
\hline Octaplex (Octapharma, Austria) & $11-38$ & $9-24$ & 25 & $18-30$ & $7-31$ & $7-32$ & $<15$ \\
\hline Prothromplex Total (Baxter, Austria) & $24-45$ & 25 & 30 & 30 & $>20$ & N.Q. & $<15$ \\
\hline PPSB-HT (Nichiyaku, Japan) & 20 & 20 & 20 & 20 & $15-45$ & N.Q. & 5 \\
\hline Cofact (Sanquin, Netherlands) & $14-35$ & $7-20$ & 25 & $14-35$ & $11-39$ & $1-8$ & None \\
\hline \multicolumn{8}{|l|}{ 3-factor PCC } \\
\hline Bebulin (Baxter, USA) & 30 & $3-5$ & 25 & 35 & N.Q. & N.Q. & 3.75 \\
\hline Profilnine (Octapharma, Austria) & 37 & 3 & 25 & 16 & N.Q. & N.Q. & None \\
\hline \multicolumn{8}{|l|}{ Activated PCC } \\
\hline FEIBA (Baxter, USA) & + & $\begin{array}{l}+ \\
\text { (FVlla) }\end{array}$ & + & $\begin{array}{l}+ \\
\text { (FXa) }\end{array}$ & N.Q. & N.Q. & None \\
\hline
\end{tabular}

Other PCC products are also available in different countries. PCCs containing heparin are contraindicated in patients with heparin-induced thrombocytopenia. The potency of each PCC vial is according to the FIX activity except for FEIBA, which is dosed according to FVIII bypassing activity unit. Data are shown based on the prescribing information for each product; actual factor contents may vary for each vial.

$P C / P S$ protein C/protein S, N.Q. not quantified. 


\section{FVII Level}

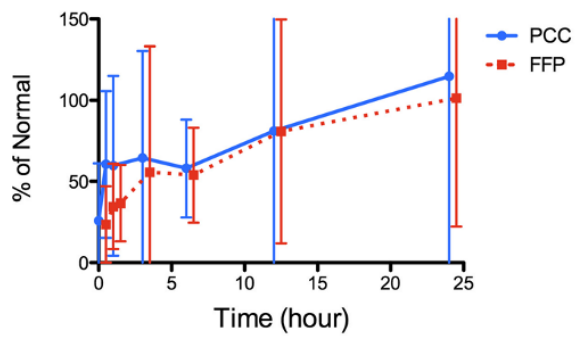

FX Level

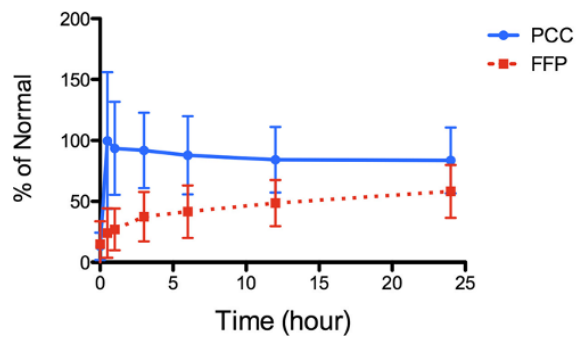

FIX Level

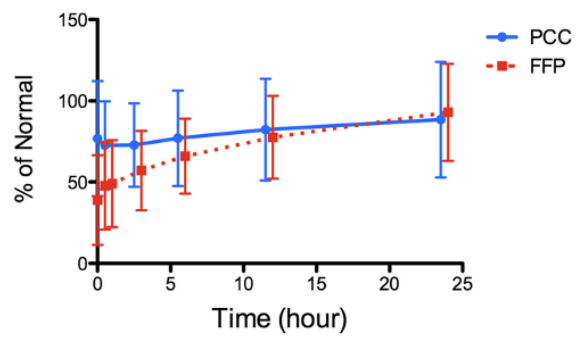

Prothrombin Level

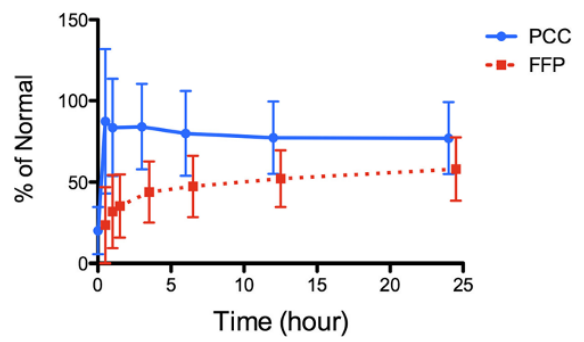

Figure 1 Coagulation factor levels in warfarin-treated patients who received 4-factor PCC or plasma transfusion. Mean plasma coagulation factor levels (\% of normal activity \pm standard deviation [SD]) for FVII, FIX, FX, and prothrombin (FII) are shown over $24 \mathrm{~h}$ after the injection of 4-factor PCC (4 F-PCC) or plasma transfusion. The elapsed time (h) from the treatment is indicated on the horizontal axis. Adapted from the reference [10] with permission.

\section{PCCs in acquired, non-warfarin coagulopathy}

The FDA-approved indication for 4-factor PCC is limited to warfarin-related bleeding, but a number of publications have described the use of PCCs in acquired, non-warfarin coagulopathy in major trauma and surgery [32-35]. In contrast to warfarin anticoagulation in which only vitamin $\mathrm{K}$ dependent factors are affected, perioperative coagulopathy often involves deficiencies of multiple coagulation factors and inhibitors. Multifactorial coagulation defects including thrombocytopenia, hypofibrinogenemia, and hyperfibrinolysis are important conditions that potentially decrease the efficacy of PCCs. These conditions can be quickly assessed by the use of whole blood viscoelastic tests. Thromboelastography (TEG ; Haemoscope-Haemonetics, Niles, IL) and thromboelastometry (ROTEM ${ }^{\circ}$, Durham, NC) are commercially available viscoelastic monitoring devices. Clot formation is assessed by the tensile (viscoelastic) force between the cup and the immersed pin resulting from the interaction between polymerizing fibrin and activated platelet glycoprotein (GP) IIb/IIIa receptors during endogenous thrombin generation and, if any, fibrin degradation by plasmin (Figure 2) [36].

In a retrospective study of 131 trauma patients (injury severity score, $38 \pm 15$ ), Schöchl et al. utilized a thromboelastometry-based protocol to initially restore fibrinogen to $150-200 \mathrm{mg} / \mathrm{dl}$ (target fibrinogen thromboelastometry [FIBTEM $\mathrm{MCF}_{\mathrm{MC}}>10 \mathrm{~mm}$ ]) and then corrected slow blood coagulation (i.e., enzymatic defect) by administering 4-factor PCC (target extrinsic thromboelastometry $\left[\right.$ EXTEM $\left._{\mathrm{CT}} \leq 80 \mathrm{~s}\right]$ ) [32]. Fibrinogen concentrate (median,
$6 \mathrm{~g}$ or approximately $75.9 \mathrm{mg} / \mathrm{kg}$ ) and 4-factor PCC (median, $1,800 \mathrm{IU}$ or approximately $22.8 \mathrm{IU} / \mathrm{kg}$ ) were respectively used in $96.2 \%$ and $73.7 \%$ of the subjects. On the other hand, platelet and plasma transfusions were given in $21.8 \%$ and $9.0 \%$ of the subjects, respectively. The overall mortality rate was $24.4 \%$, which was considered to be lower than predicted mortalities (28\%-34\%) based on the injury scales.

In cardiac surgery with a moderate to high risk of postoperative bleeding, Weber et al. recently demonstrated that thromboelastometry-guided hemostatic intervention $(n=50)$ was superior to the transfusion guided by conventional coagulation tests (control, $n=50$ ) [34]. In the intervention group, 4-factor PCC $(25 \mathrm{IU} / \mathrm{kg})$ was administered in the presence of slow blood coagulation $\left(\right.$ EXTEM $_{\mathrm{CT}}>80 \mathrm{~s}$ ) and normal fibrin formation (FIB$\mathrm{TEM}_{\mathrm{A} 10}>10 \mathrm{~mm}$ ), while in the control group, plasma or PCC was given if INR $>1.4$ or after four units of RBCs were transfused when INR was unavailable. The overall use of PCC was similar between the two groups ( $44 \%$ vs. $52 \%$ in the control; $P=0.433$ ), but the incidence of plasma transfusion was significantly decreased in the intervention group ( $40 \%$ vs. $80 \%$ in the control; $P<0.001$ ). Similarly, there are two studies involving the deep hypothermic circulatory arrest, which demonstrated that plasma usage could be significantly decreased by thromboelastometry-guided hemostatic intervention compared to the conventional transfusion. Girdauskas et al. reported that incidences of plasma, fibrinogen, and 4-factor PCC usages (thromboelastometry vs. control) were $33 \%$ vs. $86 \%(P<0.001), 78 \%$ vs. $90 \%(P=0.7)$, 


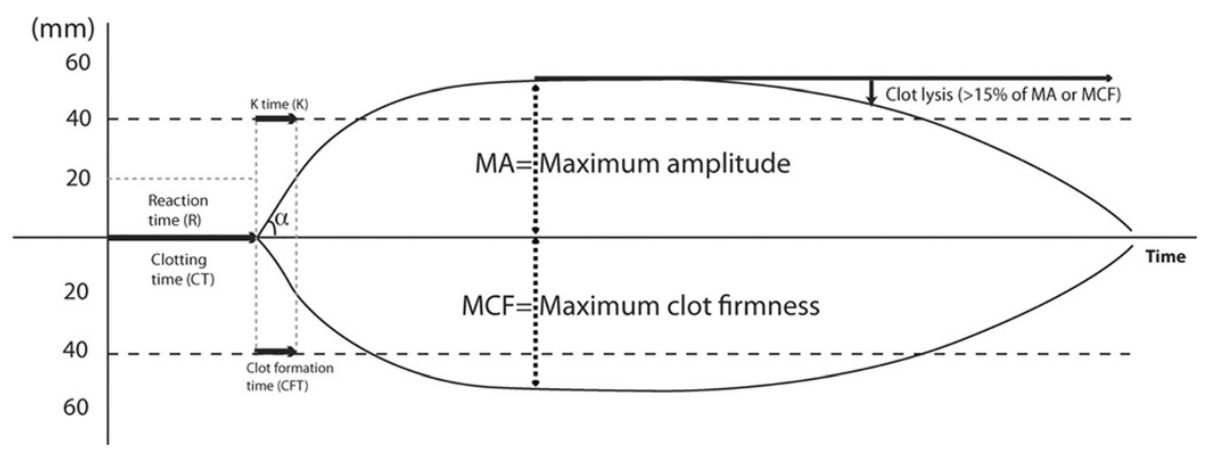

Figure 2 Basic tracing patterns. Changes in whole blood viscoelasticity are detected electromechanically in TEG ${ }^{\circledR}$ and optically in ROTEM ${ }^{\circledR}$, and clot formation parameters are generated on TEG ${ }^{\circledR}$ (top) and ROTEM ${ }^{\circledR}$ (bottom). Plasmatic coagulation is reflected on R time and CT, initial clot development is shown on $\mathrm{K}$ time or CFT (also on a angle), and maximal viscoelasticity is defined by maximum amplitude (MA) or maximum clot firmness (MCF) for TEG ${ }^{\circledR}$ and ROTEM ${ }^{\circledast}$, respectively. Systemic fibrinolysis is suspected when clot breakdown (>15\% of MA or MCF) is observed within $1 \mathrm{~h}$.

and $15 \%$ vs. $90 \%(P<0.001)$ in aortic surgery $(n=56)$ [37]. Similarly, Fassl et al. reported that plasma usage was $33 \%$ in the thromboelastometry group compared to $65 \%$ in the control $(P=0.005)$ while there was no difference in the use of fibrinogen and 4-factor PCC between the two groups in aortic surgery [35]. Although sample sizes were relatively small $(n \leq 100)$ in the three cardiac surgery studies mentioned above, in-hospital adverse events including surgical reexploration, myocardial infarction, renal impairment, stroke, and death did not appear to be increased by the thromboelastometrybased intervention. In general, the overall incidence of PCC-related thromboembolic complications was reported to be $1.4 \%(95 \% \mathrm{CI}, 0.8-2.1)$ in a recent metaanalysis of 27 studies (1,032 patients) including both 3factor and 4-factor PCCs for the reversal of vitamin K antagonists [38]. Taken together, the abovementioned trauma and cardiac surgery studies suggested that factor concentrates can be effectively combined with allogeneic components using thromboelastometry-based protocols, resulting in reduced plasma transfusion [39].

\section{Reversal of novel oral anticoagulant}

The use of novel oral anticoagulants (NOACs) is rapidly growing as an alternative to warfarin in venous thromboprophylaxis or stroke prevention in non-valvular atrial fibrillation. The direct thrombin inhibitor (anti-IIa), dabigatran, and the direct Xa inhibitor (anti-Xa) including rivaroxaban, apixaban, and edoxaban are prescribed without the need for coagulation testing. However, the lack of direct antidotes makes it difficult to manage their bleeding complications and to urgently reverse their effect for invasive procedures. Although there are specific neutralizing agents for anti-IIa and anti-Xa agents in clinical development $[40,41]$, physicians presently struggle with managing bleeding complications of NOACs, particularly of dabigatran [42-45]. The use of rFVIIa and PCCs are considered to mitigate NOAC-associated bleeding, and they have been tested in animal and preclinical studies [46,47]. However, there are few data to support their clinical applicability. A case of massive transfusion related to dabigatran was reported in a patient undergoing aortic valve replacement and coronary artery bypass surgery. An extremely high-dose rFVIIa $(21.6 \mathrm{mg}$ or $270 \mu \mathrm{g} / \mathrm{kg}$ ) was used in parallel with large amounts of blood products (plasma 22 units, cryoprecipitate 50 units, and platelets 5 adult doses), and bleeding was reported to be decreased. Hemostasis was finally achieved after several hours of hemodialysis for dabigatran removal. Another dabigatran-associated bleeding was reported after a cardiac perforation during an attempted atrial fibrillation ablation. Hypotension due to cardiac tamponade required epinephrine infusion, $8 \mathrm{l}$ of fluid administration, six units of RBCs, and two units of FFP. After more than $4.5 \mathrm{l}$ of blood was drained via pericardiocentesis, activated PCC (FEIBA, $26 \mathrm{U} / \mathrm{kg}$ ) was intravenously given, and "notable slowing of bleeding" was observed by the cardiologist. Epinephrine infusion was subsequently stopped. There was another episode of hypotension $30 \mathrm{~h}$ after the procedure, the second dose of activated PCC (16 U/kg) was administered for suspected bleeding, and no thrombotic complication was observed. In vitro studies in human plasma suggest that both rFVIIa $(120 \mu \mathrm{g} / \mathrm{kg}$ equivalent) and activated PCC (40-160 U/kg equivalent) improve the initiation of thrombin generation which is delayed by dabigatran [48]. Dabigatran-induced delayed thrombin generation was not improved by 4-factor PCC in human plasma $[48,49]$, but several in vivo animal bleeding models support the use of 4-factor and 3-factor PCCs [50,51]. There are conflicting data regarding the use of PCCs in rivaroxaban-induced bleeding [52-54]. Taken together, 
the use of rFVIIa, PCC, and activated PCC may at least partially improve hemostasis in the presence of NOACs, but there is a paucity of clinical data to suggest a specific agent and dose. It is recommended that an emergency protocol for NOAC-associated bleeding is established at each institution by combining supportive measures and pharmacological interventions [55].

\section{Selecting plasma versus PCC in complex bleeding conditions}

Clinical evidence and data supporting the use of factor concentrates in acquired coagulopathy have been increasing, but choosing this approach over plasma transfusion depends heavily on the clinical context. Although certain coagulation factors may be rapidly replenished by factor concentrates, they can be depleted again if there is no surgical control of bleeding. Durila and Malosek recently described the case of a 33-year-old woman who suffered from multiple traumatic injuries (ISS, 59) after a motor vehicle collision [56]. This patient required endotracheal intubation in the field and was brought to the hospital in hemorrhagic shock ( $\mathrm{pH} 7.0$, base excess $-18.5 \mathrm{mmol} / \mathrm{l}$ ) requiring norepinephrine to sustain blood pressure (70/ $40 \mathrm{mmHg}$ ). The obvious injury sites were an occipital open cranial wound and open fracture of the left thigh. In addition, free fluid was detected in the peritoneal cavity by ultrasound. The initial thromboelastometry traces showed delayed coagulation (EXTEM ${ }_{\mathrm{CT}} 112 \mathrm{~s}$; normal 35-80 s), late fibrinolysis on EXTEM, and borderline fibrinogen (FIBTEM ${ }_{\mathrm{MCF}} 7 \mathrm{~mm}$; normal 9-25 mm) (Figure 3A). The initial hemostatic intervention included $2 \mathrm{~g}$ of tranexamic acid, $4 \mathrm{~g}$ of fibrinogen (Haemocomplettan, CSL Behring, Germany), and four units of FFP and RBCs. The 1:1 ratio transfusion of FFP and RBCs was continued while intraabdominal and intracranial bleeding sources were sought and repaired by the surgical team. After an hour, the repeat thromboelastometry showed delayed coagulation $\left(\right.$ EXTEM $\left._{\mathrm{CT}} 114 \mathrm{~s}\right)$, thrombocytopenia $\left(\right.$ EXTEM $_{\mathrm{MCF}}$ $35 \mathrm{~mm}$; normal 53-72 $\mathrm{mm}$ ), and hypofibrinogenemia (FIBTEM MCF $5 \mathrm{~mm}$ ) (Figure 3B). The complex coagulopathy was managed with 1,200 units of 4-factor PCC (Prothromplex Total; Baxter, Austria), four units of random donor platelets, and an additional $4 \mathrm{~g}$ of fibrinogen. The combined hemostatic therapies normalized thromboelastometry parameters (Figure 3C,D), but the patient remained hemodynamically unstable, requiring continued norepinephrine infusion. This prompted the care team to look for another source of surgical bleeding, and splenic bleeding and intracranial bleeding sites were newly found by the contrast-enhanced computed tomography. After these were repaired, the patient became stable. Over the course of 8 h, 30 units of RBCs, 26 units of FFP, four units of platelets, 1,200 IU of PCC, and $10 \mathrm{~g}$ of fibrinogen were administered to this patient. In the end, the authors reported a favourable outcome of this case including no neurological deficit and no acute lung or kidney injury associated with blood transfusion [56]. Perioperative use of fibrinogen-rich components such as cryoprecipitate or fibrinogen concentrate has not been commonly used in Japan since plasma-derived (unheated) fibrinogen concentrate was recalled over hepatitis outbreak in the late 1980s [57]. However, Yamamoto et al. recently reported that the off-label use of (pathogen-inactivated) fibrinogen concentrate $(n=25)$ in thoracic aortic replacement to maintain plasma fibrinogen level of $150 \mathrm{mg} / \mathrm{dl}$ was associated with a $58 \%$ reduction in the overall requirements for RBCs, FFP, and platelets when compared to the age-matched historical control $(n=24)$ in which FFP and platelets were the only hemostatic measures [58]. Perioperative use of fibrinogen replacement can be considered as an adjunct to plasma transfusion, and the dosing can be optimized by fibrin-specific viscoelastic testing (Figure 3).

It may be argued that crystalloid and/or colloid should have been used in a complex perioperative bleeding case until surgical hemostasis is achieved instead of using allogeneic plasma. However, a large amount of crystalloid or colloid progressively worsens coagulation by dilutional effects [59] and possibly results in endothelial damage, tissue edema, and fluid overload [60]. Further, not all the coagulation factors and inhibitors can be replenished by currently available factor concentrates. Indeed, multiple microcapillary thrombi (in the lungs) and the signs of disseminated intravascular coagulation (DIC) were observed in four out of nine animals (44\%) after a high dose $(50 \mathrm{IU} / \mathrm{kg}$ ) of 4-factor PCC (Cofact; Sanquin, Netherlands) in the presence of hepatic injury and hemodilution (70\% of blood volume replacement) [61]. In their study, all nine animals that received a lower dose (35 IU/kg) of PCC had improved hemostasis (without DIC) and survival compared to the placebotreated control animals. A fatal thrombosis in the left ventricle was reported in another porcine hepatic injury model with hemodilution $(60 \%-70 \%$ of blood volume replacement) after coadministration of $200 \mathrm{mg} / \mathrm{kg}$ of fibrinogen (Haemocomplettan; CSL Behring, Germany) and $35 \mathrm{IU} / \mathrm{kg}$ of 4-factor PCC (Beriplex; CSL Behring, Germany) [62]. These preclinical data suggest that anticoagulant contents in 4-factor PCCs (mainly protein C and protein S) may be inadequate to reestablish the balance of procoagulant and anticoagulant elements in the setting of severe hemodilution ( $>70 \%$ of blood volume replacement). The 1:1 ratio transfusion of FFP and RBCs may not result in the establishment of hemostasis in the presence of massive bleeding. However, it is speculated that transfused plasma prevents excessive hemodilution of procoagulant and anticoagulant proteins [63,64], making subsequent procoagulant interventions (PCC and rFVIIa) more effective and less thrombogenic [65]. 


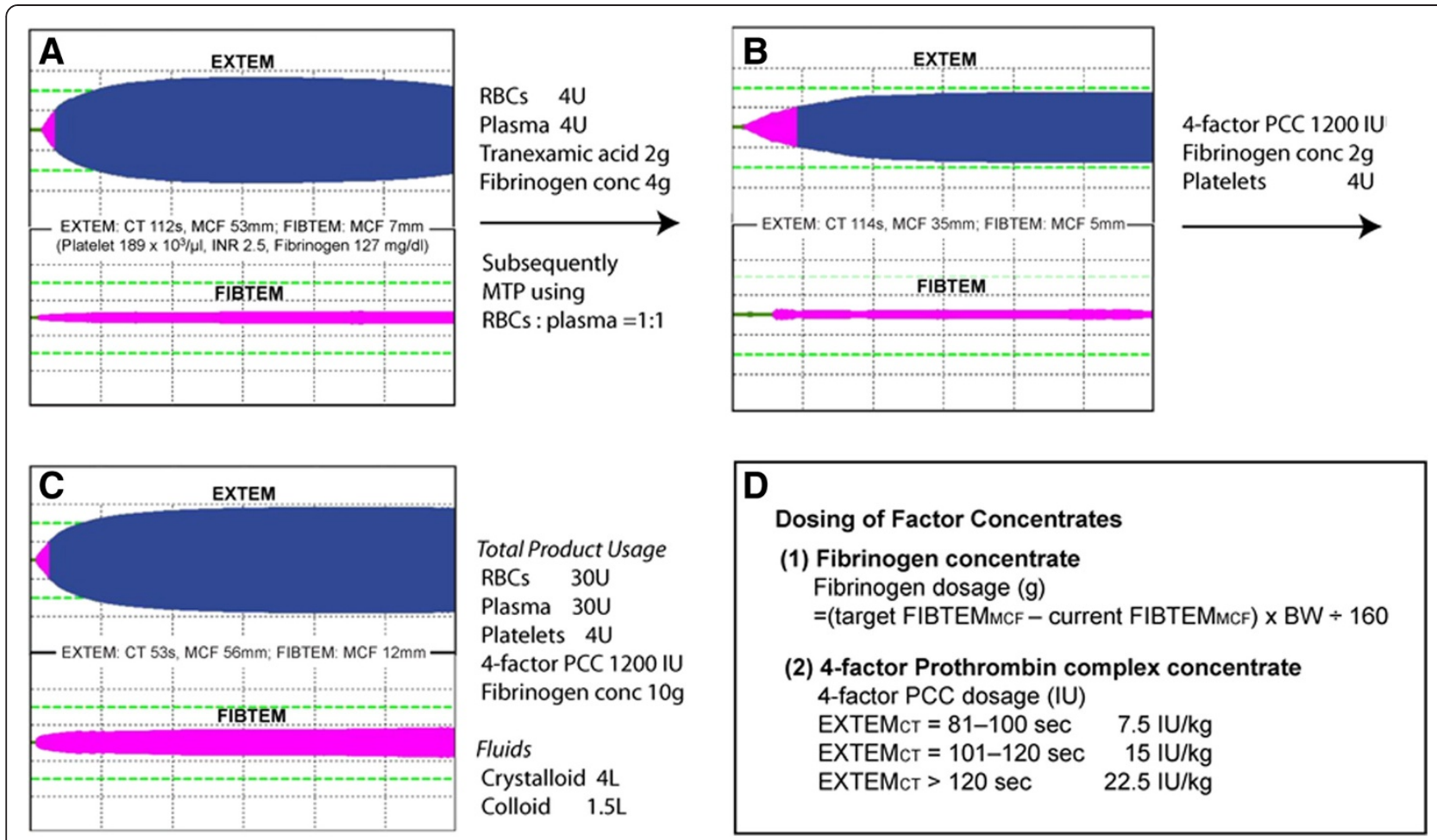

Figure 3 Examples of rotational thromboelastometric tracings. (A) Pre-treatment: traces obtained from a bleeding patient who incurred major trauma. Prolonged clotting time (CT) and late clot breakdown are notable on EXTEM. Fibrinogen level was on the borderline based on FIBTEM. Laboratory coagulation results were shown, but these results were not reported until the second ROTEM measurements were completed. Normal ranges for EXTEM and FIBTEM are as follows: EXTEM-CT 42-74 s, $\mathrm{A}_{10} 43-65 \mathrm{~mm}$, and MCF 49-71 mm; FIBTEM-A 10 9-24 mm, MCF 9-25 mm. (B) On treatment: traces obtained after the initial treatment with $2 \mathrm{~g}$ of tranexamic acid and $4 \mathrm{~g}$ of fibrinogen along with ongoing 1:1 transfusion of RBCS and plasma. No improvement was seen in CT and MCF values of EXTEM. Fibrin polymerization was worsened on FIBTEM. (C) Normalized coagulation: traces obtained after the combined therapies using 1,200 IU of 4-factor PCC, $2 \mathrm{~g}$ of fibrinogen, and four units of platelets. Despite normal traces of EXTEM and FIBTEM, bleeding continued, and additional surgical hemostasis was established over the course of $8 \mathrm{~h}$. The combination of allogeneic blood products and factor concentrates was crucial for managing massive volume depletion and ongoing bleeding. (D) Dosing of factor concentrates: the dose calculations for PCC and fibrinogen concentrate used in the protocol. BW = body weight. Adapted from the reference [56] with permission. MTP = massive transfusion protocol.

\section{Conclusions}

The goal of hemostasis is to establish adequate fibrin polymerization at the site of vascular injury in a timely fashion. Hemostatic processes are obviously complex, involving vascular, humoral, and cellular components [66]. Perioperative coagulopathy often involves multifactorial defects in vascular (e.g., surgical bleeding), humoral, and cellular components. Transfusion algorithms based on thromboelastometry have become popular because this viscoelastic testing shows the extent of fibrin polymerization and the contributions of thrombin generation and platelet numbers to clot formation $[36,67]$. Timely diagnosis and therapeutic interventions are pivotal in restoring hemostatic function and hemodynamic stability in critically ill patients after trauma and major surgery [68]. The uses of PCCs and fibrinogen concentrate have advantages over allogeneic plasma in its rapid availability and restoration of target factor(s) and lower risks for volume overload and TRALI $[10,69]$. However, there should be a careful consideration in the dosing of PCCs because the risk of thrombosis may be enhanced in a subset of trauma and surgical patients [70] due to circulating tissue factor [17] and decreased plasma or endothelial anticoagulant activity [71]. In the early phase of hemostatic therapy after massive hemorrhage, plasma transfusion can be used to sustain procoagulant and anticoagulant factor levels. Once surgically correctable bleeding sites are found and nearly repaired, factor concentrate therapy can be implemented to optimize thrombin generation and fibrin polymerization under the guidance of thromboelastometry. In many countries, perioperative uses of PCCs and fibrinogen are considered as 'off-label', but accumulating clinical data indicate that they are useful adjuncts in the management of preoperative coagulation.

\section{Competing interests}

KT has served as a consultant for TEM International (Munich, Germany), Grifols (Research Triangle Park, NC), and Octapharma (Hoboken, NJ). None of the companies were involved in the manuscript preparation. 


\section{Authors' contributions}

$\mathrm{KT}$ is the archival author and attests to the integrity of the presented data in this manuscript. This author helped with the concept of the review and the manuscript preparation. MM conducted the literature search and participated in the manuscript preparation. MD provided the clinical information and participated in the manuscript preparation. All authors read and approved the final manuscript.

\section{Author details}

'Department of Anesthesiology, Cardiothoracic Anesthesia Division, University of Maryland, Suite S8D12, 22 South Greene Street, Baltimore, MD 21201, USA. ²Department of Anesthesiology and Critical Care Medicine, Second Faculty of Medicine, Charles University, Prague, Czech Republic.

Received: 3 September 2014 Accepted: 17 October 2014

Published online: 29 October 2014

\section{References}

1. Holcomb JB, Wade CE, Michalek JE, Chisholm GB, Zarzabal LA, Schreiber MA Gonzalez EA, Pomper GJ, Perkins JG, Spinella PC, Williams KL, Park MS: Increased plasma and platelet to red blood cell ratios improves outcome in 466 massively transfused civilian trauma patients. Ann Surg 2008 248:447-458.

2. Inaba K, Lustenberger T, Rhee $P$, Holcomb JB, Blackbourne LH, Shulman Nelson J, Talving P, Demetriades D: The impact of platelet transfusion in massively transfused trauma patients. J Am Coll Surg 2010, 211:573-579.

3. Inaba K, Branco BC, Rhee P, Blackbourne LH, Holcomb JB, Teixeira PG, Shulman I, Nelson J, Demetriades D: Impact of plasma transfusion in trauma patients who do not require massive transfusion. J Am Coll Surg 2010, 210:957-965.

4. Watson GA, Sperry JL, Rosengart MR, Minei JP, Harbrecht BG, Moore EE, Cuschieri J, Maier RV, Billiar TR, Peitzman AB: Fresh frozen plasma is independently associated with a higher risk of multiple organ failure and acute respiratory distress syndrome. J Trauma 2009, 67:221-227.

5. Inaba K, Branco BC, Rhee P, Holcomb JB, Blackbourne LH, Shulman I, Nelson J, Demetriades D: Impact of ABO-identical vs ABO-compatible nonidentical plasma transfusion in trauma patients. Arch Surg 2010, 145:899-906.

6. Key NS, Negrier C: Coagulation factor concentrates: past, present, and future. Lancet 2007, 370:439-448.

7. Lin DM, Murphy LS, Tran MH: Use of prothrombin complex concentrates and fibrinogen concentrates in the perioperative setting: a systematic review. Transfus Med Rev 2013, 27:91-104.

8. Tanaka KA, Esper S, Bolliger D: Perioperative factor concentrate therapy. $\mathrm{Br} J$ Anaesth 2013, 111(Suppl 1):i35-i49.

9. Levi M, Levy JH, Andersen HF, Truloff D: Safety of recombinant activated factor VII in randomized clinical trials. N Engl J Med 2010, 363:1791-1800.

10. Sarode R, Milling TJ Jr, Refaai MA, Mangione A, Schneider A, Durn BL, Goldstein JN: Efficacy and safety of a 4-factor prothrombin complex concentrate in patients on vitamin $\mathrm{K}$ antagonists presenting with major bleeding: a randomized, plasma-controlled, phase IIlb study. Circulation 2013, 128:1234-1243

11. Chhibber V, Greene M, Vauthrin M, Bailey J, Weinstein R: Is group A thawed plasma suitable as the first option for emergency release transfusion? Transfusion 2014, 54:1751-1755.

12. Mehr CR, Gupta R, von Recklinghausen FM, Szczepiorkowski ZM, Dunbar NM: Balancing risk and benefit: maintenance of a thawed group $A$ plasma inventory for trauma patients requiring massive transfusion. J Trauma Acute Care Surg 2013, 74:1425-1431.

13. Thiele T, Kellner S, Hron G, Wasner C, Nauck M, Zimmermann K, Wessel A, Warkentin TE, Greinacher A, Selleng K: Storage of thawed plasma for a liquid plasma bank: impact of temperature and methylene blue pathogen inactivation. Transfusion 2012, 52:529-536.

14. Downes KA, Wilson E, Yomtovian R, Sarode R: Serial measurement of clotting factors in thawed plasma stored for 5 days. Transfusion 2001 41:570.

15. Tholpady A, Monson J, Radovancevic R, Klein K, Bracey A: Analysis of prolonged storage on coagulation factor (F)V, FVII, and FVIII in thawed plasma: is it time to extend the expiration date beyond 5 days? Transfusion 2013, 53:645-650

16. Boldt J, Huttner I, Suttner S, Kumle B, Piper SN, Berchthold G: Changes of haemostasis in patients undergoing major abdominal surgery-is there a difference between elderly and younger patients? Br J Anaesth 2001, $87: 435-440$

17. Dunbar NM, Chandler WL: Thrombin generation in trauma patients. Transfusion 2009, 49:2652-2660.

18. Cardigan R, Lawrie AS, Mackie IJ, Williamson LM: The quality of fresh-frozen plasma produced from whole blood stored at 4 degrees $C$ overnight. Transfusion 2005, 45:1342-1348.

19. Stanworth SJ: The evidence-based use of FFP and cryoprecipitate for abnormalities of coagulation tests and clinical coagulopathy. Hematology 2007, 1:179-186.

20. Chowdary P, Saayman AG, Paulus U, Findlay GP, Collins PW: Efficacy of standard dose and $30 \mathrm{ml} / \mathrm{kg}$ fresh frozen plasma in correcting laboratory parameters of haemostasis in critically ill patients. Br J Haematol 2004, 125:69-73.

21. Kor DJ, Stubbs JR, Gajic O: Perioperative coagulation management-fresh frozen plasma. Best Pract Res Clin Anaesthesiol 2010, 24:51-64.

22. Toy $P$, Gajic O, Bacchetti P, Looney MR, Gropper MA, Hubmayr R, Lowell CA, Norris PJ, Murphy EL, Weiskopf RB, Wilson G, Koenigsberg M, Lee D, Schuller R, Wu P, Grimes B, Gandhi MJ, Winters JL, Mair D, Hirschler N, Sanchez Rosen R, Matthay MA, Group TS: Transfusion-related acute lung injury: incidence and risk factors. Blood 2012, 119:1757-1767.

23. Eder AF, Dy BA, Perez JM, Rambaud M, Benjamin RJ: The residual risk of transfusion-related acute lung injury at the American Red Cross (2008-2011): limitations of a predominantly male-donor plasma mitigation strategy. Transfusion 2013, 53:1442-1449.

24. Holland L, Warkentin TE, Refaai M, Crowther MA, Johnston MA, Sarode R: Suboptimal effect of a three-factor prothrombin complex concentrate (Profilnine-SD) in correcting supratherapeutic international normalized ratio due to warfarin overdose. Transfusion 2009, 49:1171-1177.

25. Imberti D, Barillari G, Biasioli C, Bianchi M, Contino L, Duce R, D'Inca M, Gnani MC, Mari E, Ageno W: Emergency reversal of anticoagulation with a three-factor prothrombin complex concentrate in patients with intracranial haemorrhage. Blood Transfus 2011, 9:148-155.

26. Joseph B, Hadjizacharia P, Aziz H, Kulvatunyou N, Tang A, Pandit V, Wynne J, O'Keeffe T, Friese RS, Rhee P: Prothrombin complex concentrate: an effective therapy in reversing the coagulopathy of traumatic brain injury. J Trauma Acute Care Surg 2013, 74:248-253.

27. Tanaka KA, Mazzeffi MA, Grube M, Ogawa S, Chen EP: Three-factor prothrombin complex concentrate and hemostasis after high-risk cardiovascular surgery. Transfusion 2013, 53:920-921.

28. Ogawa S, Szlam F, Ohnishi T, Molinaro RJ, Hosokawa K, Tanaka KA: A comparative study of prothrombin complex concentrates and fresh-frozen plasma for warfarin reversal under static and flow conditions. Thromb Haemost 2011, 106:1215-1223.

29. Turecek PL, Varadi K, Gritsch H, Schwarz HP: FEIBA: mode of action. Haemophilia 2004, 10(Suppl 2):3-9.

30. Wojcik C, Schymik ML, Cure EG: Activated prothrombin complex concentrate factor VIII inhibitor bypassing activity (FEIBA) for the reversal of warfarin-induced coagulopathy. Int J Emerg Med 2009, 2:217-225.

31. Reply GA, Pereira A: Cryoprecipitate versus commercial fibrinogen concentrate in patients who occasionally require a therapeutic supply of fibrinogen: risk comparison in the case of an emerging transfusiontransmitted infection. Haematologica 2008, 93:e24-e26.

32. Schöchl H, Nienaber U, Hofer G, Voelckel W, Jambor C, Scharbert G, Kozek-Langenecker S, Solomon C: Goal-directed coagulation management of major trauma patients using thromboelastometry (ROTEM)-guided administration of fibrinogen concentrate and prothrombin complex concentrate. Crit Care 2010, 14:R55.

33. Gorlinger K, Dirkmann D, Hanke AA, Kamler M, Kottenberg E, Thielmann M, Jakob H, Peters J: First-line therapy with coagulation factor concentrates combined with point-of-care coagulation testing is associated with decreased allogeneic blood transfusion in cardiovascular surgery: a retrospective, single-center cohort study. Anesthesiology 2011, 115:1179-1191.

34. Weber CF, Gorlinger K, Meininger D, Herrmann E, Bingold T, Moritz A, Cohn LH, Zacharowski K: Point-of-care testing: a prospective, randomized clinical trial of efficacy in coagulopathic cardiac surgery patients. Anesthesiology 2012, 117:531-547.

35. Fassl J, Matt P, Eckstein F, Filipovic M, Gregor M, Zenklusen U, Seeberger $M D$, Bolliger D: Transfusion of allogeneic blood products in proximal aortic surgery with hypothermic circulatory arrest: effect of 
thromboelastometry-guided transfusion management. J Cardiothorac Vasc Anesth 2013, 27:1181-1188.

36. Tanaka KA, Bolliger D, Vadlamudi R, Nimmo A: Rotational thromboelastometry (ROTEM)-based coagulation management in cardiac surgery and major trauma. J Cardiothorac Vasc Anesth 2012, 26:1083-1093.

37. Girdauskas E, Kempfert J, Kuntze T, Borger MA, Enders J, Fassl J, Falk V, Mohr FW: Thromboelastometrically guided transfusion protocol during aortic surgery with circulatory arrest: a prospective, randomized trial. J Thorac Cardiovasc Surg 2010, 140:1117-1124. e2.

38. Majeed A, Eelde A, Agren A, Schulman S, Holmstrom M: Thromboembolic safety and efficacy of prothrombin complex concentrates in the emergency reversal of warfarin coagulopathy. Thromb Res 2012, 129:146-151.

39. Bolliger D, Tanaka KA: Roles of thrombelastography and thromboelastometry for patient blood management in cardiac surgery. Transfus Med Rev 2013, 27:213-220.

40. Schiele F, van Ryn J, Canada K, Newsome C, Sepulveda E, Park J, Nar H, Litzenburger T: A specific antidote for dabigatran: functional and structural characterization. Blood 2013, 121:3554-3562.

41. Lu G, DeGuzman FR, Hollenbach SJ, Karbarz MJ, Abe K, Lee G, Luan P, Hutchaleelaha A, Inagaki M, Conley PB, Phillips DR, Sinha U: A specific antidote for reversal of anticoagulation by direct and indirect inhibitors of coagulation factor Xa. Nat Med 2013, 19:446-451.

42. Cotton BA, McCarthy JJ, Holcomb JB: Acutely injured patients on dabigatran. N Engl J Med 2011, 365:2039-2040.

43. Harper $P$, Young $L$, Merriman E: Bleeding risk with dabigatran in the frail elderly. N Engl J Med 2012, 366:864-866.

44. Garber ST, Sivakumar W, Schmidt RH: Neurosurgical complications of direct thrombin inhibitors-catastrophic hemorrhage after mild traumatic brain injury in a patient receiving dabigatran. J Neurosurg 2012, 116:1093-1096.

45. Warkentin TE, Margetts P, Connolly SJ, Lamy A, Ricci C, Eikelboom JW: Recombinant factor Vlla ( $\mathrm{rFVIla}$ ) and hemodialysis to manage massive dabigatran-associated postcardiac surgery bleeding. Blood 2012, 119:2172-2174.

46. Tanaka KA, Bolliger D: On the reversal of new oral anti-coagulants: can we simply extrapolate data from the animal models to humans? $\mathrm{Br} J$ Anaesth 2013, 110:329-332.

47. Dickneite $G$, Hoffman M: Reversing the new oral anticoagulants with prothrombin complex concentrates (PCCs): what is the evidence? Thromb Haemost 2014, 111:189-198.

48. Marlu R, Hodaj E, Paris A, Albaladejo P, Cracowski JL, Pernod G: Effect of non-specific reversal agents on anticoagulant activity of dabigatran and rivaroxaban: a randomised crossover ex vivo study in healthy volunteers. Thromb Haemost 2012, 108:217-224.

49. Eerenberg ES, Kamphuisen PW, Sijpkens MK, Meijers JC, Buller HR, Levi M: Reversal of rivaroxaban and dabigatran by prothrombin complex concentrate: a randomized, placebo-controlled, crossover study in healthy subjects. Circulation 2011, 124:1573-1579.

50. Zhou W, Schwarting S, Illanes S, Liesz A, Middelhoff M, Zorn M, Bendszus M, Heiland S, van Ryn J, Veltkamp R: Hemostatic therapy in experimental intracerebral hemorrhage associated with the direct thrombin inhibitor dabigatran. Stroke 2011, 42:3594-3599.

51. van Ryn J, Schurer J, Kink-Eiband M, Clemens A: Successful reversal of dabigatran-induced bleeding by 3-factor coagulation concentrates in a rat tail bleeding model: lack of correlation with ex vivo markers of anticoagulation. Circulation 2012, 126, A11955.

52. Godier A, Miclot A, Le Bonniec B, Durand M, Fischer AM, Emmerich J, Marchand-Leroux C, Lecompte T, Samama CM: Evaluation of prothrombin complex concentrate and recombinant activated factor VII to reverse rivaroxaban in a rabbit model. Anesthesiology 2012, 116:94-102.

53. Perzborn E, Gruber A, Tinel H, Marzec UM, Buetehorn U, Buchmueller A, Heitmeier S, Laux V: Reversal of rivaroxaban anticoagulation by haemostatic agents in rats and primates. Thromb Haemost 2013, 110:162-172.

54. Zhou W, Zorn M, Nawroth $\mathrm{P}$, Butehorn U, Perzborn E, Heitmeier S, Veltkamp $R$ : Hemostatic therapy in experimental intracerebral hemorrhage associated with rivaroxaban. Stroke 2013, 44:771-778.

55. Siegal DM, Garcia DA, Crowther MA: How I treat target-specific oral anticoagulant-associated bleeding. Blood 2014, 123:1152-1158.

56. Durila M, Malosek M: Rotational thromboelastometry along with thromboelastography plays a critical role in the management of traumatic bleeding. Am J Emerg Med 2014, 32:288. e1-3.
57. Yasunaga $\mathrm{H}$ : Risk of authoritarianism: fibrinogen-transmitted hepatitis $\mathrm{C}$ in Japan. Lancet 2007, 370:2063-2067.

58. Yamamoto K, Usui A, Takamatsu J: Fibrinogen concentrate administration attributes to significant reductions of blood loss and transfusion requirements in thoracic aneurysm repair. J Cardiothorac Surg 2014, 9:90

59. Bolliger D, Gorlinger K, Tanaka KA: Pathophysiology and treatment of coagulopathy in massive hemorrhage and hemodilution. Anesthesiology 2010, 113:1205-1219.

60. Kozar RA, Peng Z, Zhang R, Holcomb JB, Pati S, Park P, Ko TC, Paredes A: Plasma restoration of endothelial glycocalyx in a rodent model of hemorrhagic shock. Anesth Analg 2011, 112:1289-1295.

61. Grottke $O$, Braunschweig T, Spronk HM, Esch S, Rieg AD, van Oerle R, ten Cate H, Fitzner C, Tolba R, Rossaint R: Increasing concentrations of prothrombin complex concentrate induce disseminated intravascular coagulation in a pig model of coagulopathy with blunt liver injury. Blood 2011, 118:1943-1951.

62. Mitterlechner T, Innerhofer P, Streif W, Lodl M, Danninger T, Klima G, Hansson K, Fries D: Prothrombin complex concentrate and recombinant prothrombin alone or in combination with recombinant factor $\mathrm{X}$ and FVIla in dilutional coagulopathy: a porcine model. J Thromb Haemost 2011, 9:729-737.

63. Hiippala S: Replacement of massive blood loss. Vox Sang 1998, 74(Suppl 2):399-407

64. Bolliger D, Szlam F, Levy JH, Molinaro RJ, Tanaka KA: Haemodilutioninduced profibrinolytic state is mitigated by fresh-frozen plasma: implications for early haemostatic intervention in massive haemorrhage. $\mathrm{Br} \mathrm{J}$ Anaesth 2010, 104:318-325. doi: 10.1093/bja/aeq001.

65. Sniecinski R, Szlam F, Chen EP, Bader SO, Levy JH, Tanaka KA: Antithrombin deficiency increases thrombin activity after prolonged cardiopulmonary bypass. Anesth Analg 2008, 106:713-718.

66. Tanaka KA, Key NS, Levy JH: Blood coagulation: hemostasis and thrombin regulation. Anesth Analg 2009, 108:1433-1446

67. Bolliger D, Seeberger MD, Tanaka KA: Principles and practice of thromboelastography in clinical coagulation management and transfusion practice. Transfus Med Rev 2012, 26:1-13.

68. Tanaka KA, Bader SO, Sturgil EL: Diagnosis of perioperative coagulopathyplasma versus whole blood testing. J Cardiothorac Vasc Anesth 2013, 27:S9-S15.

69. Hanke AA, Joch C, Gorlinger K: Long-term safety and efficacy of a pasteurized nanofiltrated prothrombin complex concentrate (Beriplex $\mathrm{P} / \mathrm{N})$ : a pharmacovigilance study. Br J Anaesth 2013, 110:764-772.

70. Koster A, Meyer-Jark T, Schirmer U, Sandica E: Fulminant intraoperative right heart and pulmonary artery thrombosis following prothrombin complex concentrate infusion after complex open heart surgery with cardiopulmonary bypass. A\&A Case Rep 2014, 2:89-91.

71. Sniecinski RM, Chen EP, Tanaka KA: Reduced levels of fibrin (antithrombin I) and antithrombin III underlie coagulopathy following complex cardiac surgery. Blood Coagul Fibrinolysis 2008, 19:178-179.

\section{doi:10.1186/s40560-014-0060-5}

Cite this article as: Tanaka et al:: Role of prothrombin complex concentrate in perioperative coagulation therapy. Journal of Intensive Care 2014 2:60.

\section{Submit your next manuscript to BioMed Central and take full advantage of:}

- Convenient online submission

- Thorough peer review

- No space constraints or color figure charges

- Immediate publication on acceptance

- Inclusion in PubMed, CAS, Scopus and Google Scholar

- Research which is freely available for redistribution 